\title{
Sustained-release Lipid Inhaled Cisplatin
}

National Cancer Institute

\section{Source}

National Cancer Institute. Sustained-release Lipid Inhaled Cisplatin. NCI Thesaurus. Code C116884.

A sustained-release formulation for inhalation in which the inorg anic platinum $(\mathrm{Pt})$ agent cisplatin is encapsulated in lipids, with potential antineoplastic activity. Upon inhalation of the sustained-release lipid inhalation targeting (SLIT) cisplatin into the lungs, this agent forms highly reactive, positively charged, Pt complexes, which covalently bind to nucleophilic groups in DNA, preferably at the N7 position of guanine bases. Pt complex binding introduces intrastrand and interstrand DNA cross-links, and DNA-Pt-protein cross-links. These cross-links result in apoptosis and cell growth inhibition of lung cancer cells. Encasement in liposomes prolongs cisplatin's efficacy when compared to intravenously administered cisplatin; inhalation of cisplatin improves its concentration at tumor sites in the lungs while minimizing its systemic toxicity. 